\title{
Commentary: Horseshoes and hand grenades
}

\author{
Joseph S. Coselli, MD, and Alice Le Huu, MD
}

\footnotetext{
From the Division of Cardiothoracic Surgery, Michael E. DeBakey Department of Surgery, Baylor College of Medicine, Houston, Tex, Department of Cardiovascular Surgery, Texas Heart Institute, Texas Medical Center, Houston, Tex, and CHI St Luke's Health-Baylor St Luke's Medical Center, Houston, Tex.

Disclosures: Authors have nothing to disclose with regard to commercial support.

Received for publication Feb 27, 2019; accepted for publication Feb 28, 2019; available ahead of print April 10, 2019.

Address for reprints: Joseph S. Coselli, MD, Michael E. DeBakey Department of Surgery, Baylor College of Medicine, One Baylor Plaza, BCM 390, Houston, TX 77030 (E-mail: jcoselli@bcm.edu).

J Thorac Cardiovasc Surg 2020;159:32-3

$0022-5223 / \$ 36.00$

Copyright $(\underset{2019}{ } 20 \mathrm{by}$ The American Association for Thoracic Surgery

https://doi.org/10.1016/j.jtcvs.2019.02.103
}

To better understand the ideal use of neuroprotection strategies during aortic arch surgery, Hameed and colleagues $^{1}$ used an innovative new study design known as network meta-analysis, which facilitates direct and indirect comparison among multiple comparative studies within a single overarching analysis. This is a dramatic departure from established meta-analyses of aortic arch repair that rely solely on direct evidence, permitting the appraisal of only 2 modalities of cerebral protection. ${ }^{2-6}$ Use of network meta-analysis enabled Hameed and colleagues $^{1}$ to simultaneously evaluate 3 approaches to cerebral protection: antegrade cerebral perfusion (ACP), retrograde cerebral perfusion ( $\mathrm{RCP})$, and isolated deep hypothermic circulatory arrest (DHCA).

The research included 26,968 patients from 68 publications, including 6 randomized controlled trials and 62 observational studies. Their findings suggest that the use ACP or RCP did not significantly influence postoperative stroke or mortality, the duration of circulatory arrest correlated with the effect of ACP and RCP, and the use of unilateral or bilateral ACP and temperature target for circulatory arrest did not influence the operative outcomes. This supports currently available data, primarily that ACP and RCP yield superior neuroprotection results to those of isolated DHCA. ${ }^{7-9}$ Most surgeons agree that for arch repairs with short periods of cerebral ischemia (ie, $<25$ minutes), the use of either ACP, RCP, or isolated DHCA provides sufficient protection. Similarly, the consensus opinion is that for arch repairs with longer ischemic times, some sort of brain perfusion, whether it be ACP or RCP, is beneficial.

The study by Hameed and colleagues, ${ }^{1}$ although compelling, is unable to definitively determine the optimal strategy for the anticipated prolonged ischemic times necessitated by total transverse aortic arch repair. This is due to inherent limitations in the substrate data. Most publications contain a mixture of patients undergoing hemiarch and total transverse aortic arch replacement_-vastly divergent procedures that often have different neurologic outcomes. The majority

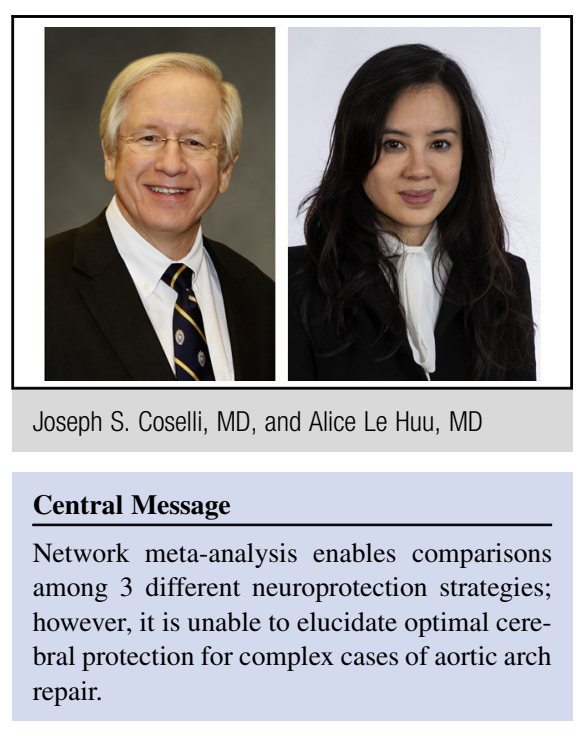

See Article page 18.

of surgeons will concur that cerebral protection strategies deemed adequate for a typical hemiarch repair may not be sufficient for more complex operations. Grouping these operations together renders it difficult to elucidate the precise role of ACP, RCP, and bilateral ACP for repairs with prolonged ischemic times. In addition, standard definitions of hypothermia are frequently absent from published studies and serve as a significant confounding variable. Following the consensus developed by Yan and colleagues ${ }^{10}$ (ie, deep hypothermia defined as $14.1^{\circ} \mathrm{C}-20^{\circ} \mathrm{C}$, moderate hypothermia as $20.1^{\circ} \mathrm{C}-28^{\circ} \mathrm{C}$, and mild hypothermia as $28.1^{\circ} \mathrm{C}-34^{\circ} \mathrm{C}$ ) would facilitate future investigations by creating a level playing field.

Currently, there is significant disparity worldwide in strategies used during aortic arch repair: flow rates, temperature targets, cannulation sites, cerebral perfusion (including unilateral or bilateral protection), and techniques for reattaching branching arteries. European surgeons favor ACP during elective cases and RCP for emergency cases, although the use of isolated DHCA is prevalent in the United States. ${ }^{7,11}$ The considerable heterogeneity in approaches emphasizes the paucity of data on the optimal cerebral protection strategy, the lack of conviction regarding the ideal approach, and the continued divergence of opinion. Despite the important contributions that Hameed and colleagues $^{1}$ bring to the surgical literature, readers remain left with a plethora of questions regarding the ideal approach to complex aortic arch repair. 


\section{References}

1. Hameed I, Rahouma M, Khan FM, Wingo M, Demetres M, Tam DY, et al. Cerebral protection strategies in aortic arch surgery: a network meta-analysis. $J$ Thorac Cardiovasc Surg. 2020;159:18-31.

2. Angeloni E, Benedetto U, Takkenberg JJ, Stigliano I, Roscitano A, Melina G, et al. Unilateral versus bilateral antegrade cerebral protection during circulatory arrest in aortic surgery: a meta-analysis of 5100 patients. J Thorac Cardiovasc Surg. 2014;147:60-7.

3. Hu Z, Wang Z, Ren Z, Wu H, Zhang M, Zhang H, et al. Similar cerebral protective effectiveness of antegrade and retrograde cerebral perfusion combined with deep hypothermia circulatory arrest in aortic arch surgery: a meta-analysis and systematic review of 5060 patients. J Thorac Cardiovasc Surg. 2014;148:544-60.

4. Takagi H, Mitta S, Ando T. A contemporary meta-analysis of antegrade versus retrograde cerebral perfusion for thoracic aortic surgery. Thorac Cardiovasc Surg. 2019;67:351-62.

5. Tian DH, Wan B, Bannon PG, Misfeld M, LeMaire SA, Kazui T, et al. A metaanalysis of deep hypothermic circulatory arrest alone versus with adjunctive selective antegrade cerebral perfusion. Ann Cardiothorac Surg. 2013;2:261-70.

6. Tian DH, Weller J, Hasmat S, Oo A, Forrest P, Kiat H, et al. Adjunct retrograde cerebral perfusion provides superior outcomes compared with hypothermic

circulatory arrest alone: a meta-analysis. J Thorac Cardiovasc Surg. 2018;156: 1339-48.

7. Englum BR, He X, Gulack BC, Ganapathi AM, Mathew JP, Brennan JM, et al. Hypothermia and cerebral protection strategies in aortic arch surgery: a comparative effectiveness analysis from the STS Adult Cardiac Surgery Database. Eur J Cardiothorac Surg. 2017;52:492-8.

8. Okita Y, Miyata H, Motomura N, Takamoto S. A study of brain protection during total arch replacement comparing antegrade cerebral perfusion versus hypothermic circulatory arrest, with or without retrograde cerebral perfusion: analysis based on the Japan Adult Cardiovascular Surgery Database. J Thorac Cardiovasc Surg. 2015;149:S65-73.

9. Shihata M, Mittal R, Senthilselvan A, Ross D, Koshal A, Mullen J, et al. Selective antegrade cerebral perfusion during aortic arch surgery confers survival and neuroprotective advantages. J Thorac Cardiovasc Surg. 2011;141:948-52.

10. Yan TD, Bannon PG, Bavaria J, Coselli JS, Elefteriades JA, Griepp RB, et al Consensus on hypothermia in aortic arch surgery. Ann Cardiothorac Surg. 2013;2:163-8.

11. De Paulis R, Czerny M, Weltert L, Bavaria J, Borger MA, Carrel TP, et al. Current trends in cannulation and neuroprotection during surgery of the aortic arch in Europe. Eur J Cardiothorac Surg. 2015;47:917-23. 